\title{
Symptomatic fibrous dysplasia of the right first rib excised via a posterolateral thoracotomy
}

\author{
JJ PAYNE-JAMES, RK WALESBY \\ From the Department of Surgery, Royal Free Hospital, London
}

Primary tumours of the first rib remain a rarity, but their diagnosis and management present difficult clinical problems. We describe the management of one such case.

\section{Case report}

A 35 year old housewife presented to her general practitioner complaining of discomfort in her right supraclavicular fossa for some weeks past. No abnormality was found on examination at this time, but a chest radiograph (fig 1) showed a $3.5 \mathrm{~cm}$ calcified expansion of the anterior end of the first rib. Radiologically this was considered to be a chondroma, although malignancy could not be excluded. On examination at this time a smooth mass could be palpated just posteriorly to the clavicle. There was no evidence of a neurovascular lesion and no regional lymphadenopathy. A mass radiograph taken five years previously showed no evidence of this lesion. In view of the recent history of pain, excision was deemed necessary to confirm the pathological nature of the mass. The anterior three quarters of the first rib, including the tumour, was excised through a posterolateral approach after division of the second rib (fig 2). Postoperative recovery was rapid and uneventful. Histological examination showed the lesion to be fibrous dysplasia. The cosmetic result was good and the patient remains well.

\section{Discussion}

Primary rib neoplasms are rare, and with neoplasms of the sternum account for about $5-10 \%$ of bony tumours. ${ }^{1}$ They present management problems because of the difficulty of assessing clinically and radiologically whether they are benign or malignant. Histological assessment is difficult with needle biopsy or incision biopsy as considerable histological variation can occur throughout the tumour. Rapid increase in volume, the development of pain, and the size itself have been suggested as indicating malignancy. From $33 \%{ }^{2}$ to $66 \%{ }^{3}$ of rib neoplasms are found to be malignant. The possible causes of a lesion such as this are many and varied and include osteochondroma, chondroma, chondrosarcoma, osteosarcoma, chondromyxoid sarcoma, fibrous dysplasia, and haemangioma. ${ }^{45}$ Fibrous dysplasia and osteochondroma are the most common benign tumours of ribs in

Address for reprint requests: Mr JJ Payne-James FRCS, Department of Surgery, Royal Free Hospital, London NW3 2QG. most series. ${ }^{56}$ The treatment for all tumours is complete excision because even some of those tumours considered to be benign have been shown to recur and undergo malignant degeneration. ${ }^{6}$ Primary malignant lesions should be widely excised so that a region including the ribs above and below the tumour is removed. ${ }^{26}$

In view of the unknown nature of the lesion in our patient, excision of the mass was considered necessary. Neoplastic lesions of the first ribs are very rarely reported, ${ }^{4}$ and surgical access to the first rib is most commonly indicated as part of the treatment for relief of the "thoracic outlet syndrome." Three approaches have been described for excision of the first rib for relief of this syndrome-the anterior, ${ }^{7}$ the transaxillary, ${ }^{8}$ and the posterolateral approach. ${ }^{9}$ The aims of treatment of the thoracic outlet syndrome are removal of enough first rib to allow decompression of the outlet and if possible to give a good cosmetic result. All three procedures have their advocates but most would agree that anterior and transaxillary approaches give a good cosmetic result. The posterolateral approach, however, has the advantage of excellent exposure of the entire first rib, especially in the obese or muscular individual. In addition, any complication of the procedure can be corrected adequately through this

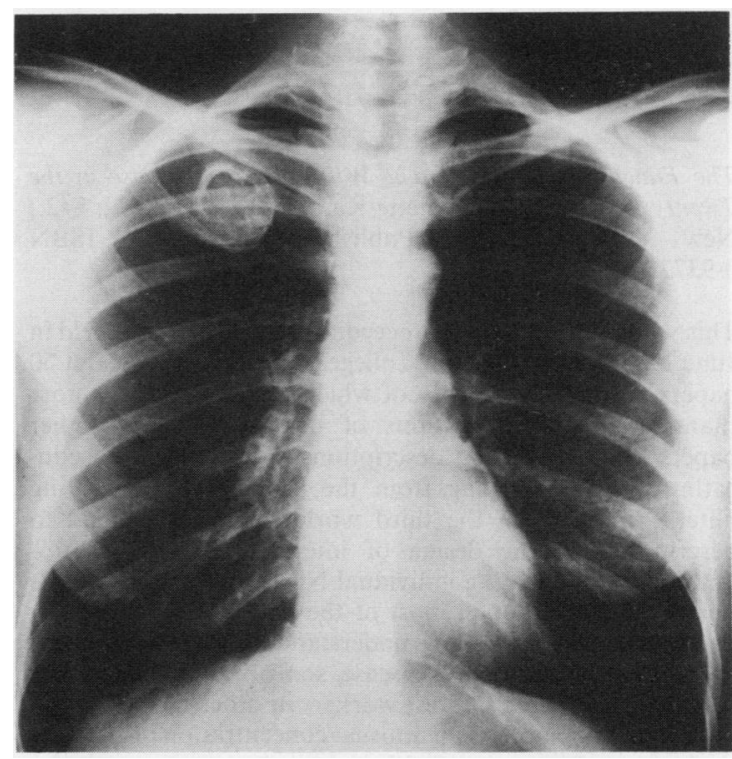

Fig 1 Preoperative chest radiograph. 


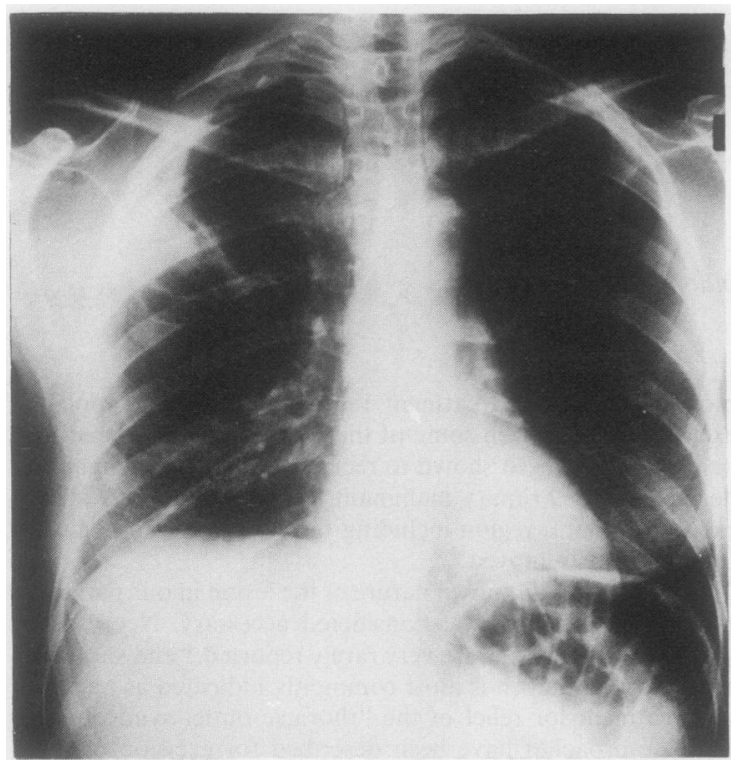

Fig 2 Postoperative chest radiograph.

incision, especially after osteotomy of the second rib. ${ }^{10}$ In view of this a posterolateral approach was preferred for our patient and first rib resection was carried out via this approach without difficulty. Postoperative recovery was uneventful and the cosmetic result was also satisfactory.
Our case illustrates the problems of management of a potentially malignant lesion in a rare and relatively inaccessible site. We would suggest that the treatment of choice for $\overrightarrow{\bar{s}}$ tumour of a first rib would be excision via a posterolateral approach

\section{References}

1 Dahlin DC. Bone tumours: general aspects and data on 3987 cases $\vec{\circ}$ 2nd ed. Springfield, Illinois: Charles C Thomas, 1967.

2 Vogt-Moyko I, Krumhaar D. Management of primary rib tumours. Surg Gynecol Obstet 1967;125:1239-45.

3 Pascuzzi CA, Dahlin DC, Clagett O. Primary tumours of the ribs and sternum. Surg Gynecol Obstet 1957:194:390-400.

4 Lawson JP, Barwick KW. Case report 209. Chondromyxoid fibroma of rib. Skeletal Radiol 1982;9:53-5.

5 Teitelbaum S. Twenty years experience with intrinsic tumours of the bony thorax at a large institution. J Thorac Cardiovasc Surg 1972;63:776-82.

6 Marcove RC, Huvos AG. Cartilaginous tumours of ribs. Cancer 1971;28:793-801.

7 Sendzischen $\mathrm{H}$, Hempel GK. Anterior approach for resection of the first rib and total scalenotomy. Surg Gynecol Obste止 1985;160:275-6.

8 Roos DB. Transaxillary approach for first rib resection to relieve $\vec{\emptyset}$ thoracic outlet syndrome. Am Surg 1966;163:354-8.

9 Johnson C. Treatment of thoracic outlet syndrome by removal of first rib and related entrapments through a posterolaterab approach. J Thorac Cardiovasc Surg 1974;68:536-45.

10 Roeder DK, Mills M, McHall JJ, Shepard BM, Ashworth HE First rib resection in the treatment of thoracic outlet syndromed Transaxillary and posterior thoracoplasty approach. Ann Surg 1973;178:49-52.

\section{Book notices}

The Education of the Patient With Cardiac Disease in the Twenty First Century. Nanette Kass Wenger. (Pp 472; \$42.) New York: Le Jacq Publishing Inc. 1986. ISBN 0-937716-24-3.

This volume contains the proceedings of a conference held in June 1985 at the American College of Cardiology. About 50 papers are included, many of which amount to little more than speculative expressions of belief and hope. Other papers offer interesting descriptions of experience in educating patients, varying from the problems of educating illiterate patients in the third world on the one hand to descriptions of the design of interactive videodisc programmes for educating individual North American patients on the other. Although most of the papers are inspired by the problem of improving understanding of the treatment and prevention of cardiac disease, some of them have wider relevance and could interest workers in other medical disciplines. The book offers an unusual concentration of the relatively few references to published work on one particular aspect of medical education - education of the patient.-AB
Comprehensive Respiratory Care-A Learning System David H Eubanks, Roger C Bone. (Pp 878; £35.50.) S Louis, Missouri: CV Mosby Company. 1985. ISBN 0-8016-1652-2.

This book is intended for a very narrow readership of respi을 ratory therapists. It is an attempt to produce a fully compren hensive learning system that encompasses everything fron? the cell to the use of drugs in cardiopulmonary resuscitation pulmonary rehabilitation, and neonatal and paediatriou respiratory care. Its comprehensive nature may be demon strated by the fact that it includes sections on how to answer the telephone and how to sit a patient up in bed. There is long section on the medicolegal consequences of accepting responsibility referred from members of the medical profession. Each chapter starts with a list of learning objectiveș and ends with a series of tabulated procedures. It is pros fusely illustrated. Discussion with a senior physiotherapis supports the view that it is unlikely that such a book will fin a market in the United Kingdom, where there are no equiv $\frac{0}{9}$
alents of the respiratory therapist. - JCS 